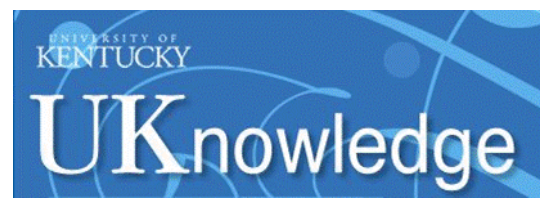

University of Kentucky

UKnowledge

\title{
Lower Gastrointestinal Bleeding and Paroxetine Use: Two Case Reports
}

\author{
Hilario Blasco-Fontecilla \\ Autonoma University, Spain \\ Jose de Leon \\ University of Kentucky, jdeleon@uky.edu
}

Follow this and additional works at: https://uknowledge.uky.edu/psychiatry_facpub

Part of the Psychiatry and Psychology Commons

Right click to open a feedback form in a new tab to let us know how this document benefits you.

\section{Repository Citation}

Blasco-Fontecilla, Hilario and de Leon, Jose, "Lower Gastrointestinal Bleeding and Paroxetine Use: Two Case Reports" (2012). Psychiatry Faculty Publications. 13.

https://uknowledge.uky.edu/psychiatry_facpub/13

This Article is brought to you for free and open access by the Psychiatry at UKnowledge. It has been accepted for inclusion in Psychiatry Faculty Publications by an authorized administrator of UKnowledge. For more information, please contact UKnowledge@lsv.uky.edu. 


\section{Lower Gastrointestinal Bleeding and Paroxetine Use: Two Case Reports}

Digital Object Identifier (DOI)

http://dx.doi.org/10.1016/j.psym.2011.09.002

\section{Notes/Citation Information}

Published in Psychosomatics, v. 53, issue 2, p. 184-187.

Copyright @ 2012 The Academy of Psychosomatic Medicine. Published by Elsevier Inc. All rights reserved.

This manuscript version is made available under the CC-BY-NC-ND 4.0 license. 


\section{Word count: 1627 words in the text and 20 references}

TITLE: Lower gastrointestinal bleeding and paroxetine use: two case reports. RUNNING TITLE: Lower gastrointestinal bleeding and paroxetine use

Hilario Blasco-Fontecilla ${ }^{1,2} \mathrm{MD}, \mathrm{PhD}$, Jose de Leon $^{3 *} \mathrm{MD}$

${ }^{1}$ Department of Psychiatry, Jimenez Diaz Foundation, IIS, Autonoma University, CIBERSAM, Madrid, Spain.

${ }^{2}$ Service de Psychologie Médicale \& Psychiatrie, INSERM U 888, Hôpital Lapeyronie. CHU Montpellier 34295 Cedex 5, France

${ }^{3}$ Mental Health Research Center at Eastern State Hospital, Lexington, Kentucky, U.S.

* Corresponding author to whom reprint requests should be sent:

Jose de Leon M.D.

Mental Health Research Center at Eastern State Hospital, 627 W Fourth St, Lexington, KY 40508, USA email: jdeleon@uky.edu

Disclosure: This article was written with no external support and no commercial organizations had any role in the writing of this paper for publication. The authors report no proprietary or commercial interest in any product mentioned or concept discussed in this article. Dr. Blasco-Fontecilla acknowledges the Spanish Ministry of Health (Rio Hortega CM08/00170), Alicia Koplowitz Foundation, and Conchita Rabago Foundation for funding his post-doctoral stage at CHRU, Montpellier, France. The authors acknowledge Lorraine Maw, M.A., and Margaret T. Susce, M.L.T, R,N., who helped in editing the article. 


\begin{abstract}
Background: Selective serotonin reuptake inhibitors (SSRIs) have been associated with depletion of serotonin in platelets, and risk of bleeding. Objective: The main objective is to report the cases of two young males with no medical problems other than their psychiatric disorders presenting with lower gastrointestinal bleeding after paroxetine use. Method: We report two cases of lower gastrointestinal bleeding in young, healthy subjects, after the use of low-medium doses of paroxetine. Results: The scarce literature available suggests that SSRIs in general, and paroxetine in particular, increase the risk of lower gastrointestinal bleeding. Conclusion: SSRIs have been associated with upper gastrointestinal bleeding but they also appear to be associated with lower gastrointestinal bleeding. Careful monitoring is particularly advisable during the initial period of use. Prospective studies are warranted to confirm the relationship between SSRI use and lower gastrointestinal bleeding.
\end{abstract}

KEY WORDS: paroxetine, selective serotonin reuptake inhibitors, lower gastrointestinal bleeding 
Paroxetine is a selective serotonin reuptake inhibitor (SSRI), and an effective long-term treatment for social anxiety and major depression. ${ }^{1}$ SSRIs in general, and paroxetine in particular, were described as associated with depletion of serotonin in platelets. $^{2}$ Serotonin is involved in platelet aggregation, ${ }^{1}$ and the association of bleeding to SSRI use was suggested two decades ago. ${ }^{3}$ In the last few years, some reviews have confirmed that initial fear. ${ }^{1,4}$ In contrast with aspirin, SSRIs seem to be related to nonulcer, non-variceal gastrointestinal bleeds. ${ }^{5}$ SSRIs are usually associated with upper gastrointestinal bleeding but there is surprisingly little literature on lower gastrointestinal bleeding (LGIB) associated with SSRI use. ${ }^{1}$ The annual incidence of LGIB is approximately 20-30 cases per 100,000 inhabitants in Western countries; the incidence increases with age. ${ }^{6}$ We present two young males with no medical problems besides their psychiatric diagnoses presenting with LGIB after paroxetine use.

\section{Case reports}

Case 1. Mr. A is a 28-year-old Caucasian Dutch male who was treated for a panic disorder without agoraphobia with paroxetine titrated up to $40 \mathrm{mg} /$ day. Five weeks after the onset of the paroxetine treatment and one week after the $40 \mathrm{mg} / \mathrm{dose}$ was reached, he presented with six episodes of sudden auto-limited LGIB, constipation and mild tremor. He was otherwise healthy, and used no medications or illegal drugs. As the patient did not relate paroxetine use with the LGIB episodes and did not see any physician at this time, he continued using paroxetine. Two weeks later, he underwent a series of routine haematological examinations after a consultation with his family doctor. All of them were normal and included: platelet count $\left(306,000 / \mathrm{mm}^{3}\right.$, normal laboratory range $\left.=130,000-400,000 / \mathrm{mm}^{3}\right)$, the international normalized ratio $(\mathrm{INR})=1$ and the remaining usual coagulation parameters; hemogram, iron, and ferritin; proteinogram, glucose, lipids, thyroid-stimulating hormone (TSH), thyroid hormones, 
hepatic and renal parameters were also normal. A fecal occult blood test was negative. Visual inspection ruled out external hemorrhoids. Using anoscopy to rule out internal hemorrhoids was not considered because the patient lacked any risk factors and presented with no symptoms suggestive of them such as rectal pain, itching or hematochezia. The bleeding source was not identified. The paroxetine dosage was decreased to $20 \mathrm{mg} /$ day and combined with $15 \mathrm{mg} /$ day of mirtazapine with full remission of his symptoms after psychiatric consultation. After a one-year follow-up the patient did not report any further bleeding episodes.

Case 2. Mr. B is a 20-year-old Spanish Caucasian male who was treated for a mild to moderate major depressive disorder, single episode, with paroxetine titrated up to 20 $\mathrm{mg} /$ day. Besides the depressive episode, he was healthy, and was taking no medications or illegal drugs. Two weeks after starting paroxetine use and five days after reaching the $20 \mathrm{mg} /$ day dose, he developed mild tremor and headache, and an episode of moderate LGIB. He underwent a series of routine hematological examinations in the emergency department. All routine hematological examinations including platelet count were normal $\left(298,000 / \mathrm{mm}^{3}\right.$ x $10^{9} /$ liter; normal laboratory range $\left.=120,000-450,000 / \mathrm{mm}^{3}\right)$. However, the activated partial thromboplastin time (40.23 seconds; reference laboratory range $=22.5-38.0$ seconds), and INR (1.28; reference laboratory range $=0.71-1.20$ ) were slightly elevated. Lupus anticoagulant testing was negative. Visual inspection and anoscopy ruled out external and internal hemorrhoids, respectively. No bleeding source was identified. As the patient did not attribute the LGIB to the paroxetine use, he decided on his own to continue using paroxetine in the same dose of $20 \mathrm{mg} / \mathrm{d}$. He only disclosed the LGIB episode to his psychiatrist several months after the episode. He presented no further episodes of bleeding in the year following the LGIB episode. 


\section{Discussion}

Both patients were young, medically healthy subjects in monotherapy with paroxetine and other potential causes of bleeding, including hemorrhoidal bleeding, were excluded. The close temporal relationship between paroxetine use and LGIB suggested that the bleeding was possibly secondary to the use of paroxetine. Although an etiological relationship between paroxetine use and LGIB cannot be drawn from either case, the Naranjo probability scale $^{7}$ score was 7 in both patients, suggesting a probable relationship between the LGIB and paroxetine use.

Our case reports are interesting for at least two reasons. First, because they give further support to a putative relationship between SSRI use and LGIB. Recent studies have confirmed previous safety concerns about the increased risk of bleeding, particularly in the upper gastrointestinal tract, among SSRI users ${ }^{1,8}$ with a range of 1/100 to $1 / 1000$ patients/year of exposure among SSRI users. ${ }^{4}$ A recent report has also suggested an increased risk of LGIB among SSRI users. ${ }^{9}$ Unfortunately, there is little literature available on the relationship between SSRIs and LGIB, and the few available studies are retrospective. ${ }^{5,9}$ Second, the clinical data here reported provide interesting insights about the relationship between paroxetine use and bleeding. Thus, both patients presented the LGIB episodes using low-medium paroxetine doses, during the initial months of paroxetine use, and neither of them presented with any further bleeding episodes in the year following the initial bleeding episode, despite the fact that both continued using paroxetine. It is important to remember that neither dose nor duration of SSRI use has been associated with bleeding risk. ${ }^{4}$ SSRIs inhibit the uptake of serotonin by platelets, and impair platelet aggregation and hemostasis. Even lowmedium doses of SSRIs can reduce serotonin content in more than $80 \%$ of subjects. ${ }^{10}$ In a 2-week randomized double-blind placebo-controlled study in healthy male volunteers 
receiving paroxetine (20 $\mathrm{mg} / \mathrm{day})$, there was an important $(83 \%)$ decrease in intraplatelet serotonin concentrations, reduced platelet plug formation, and prolongation of closure time. ${ }^{11}$ In another study with nineteen drug-free psychiatric outpatients initially tested before and after six weeks of paroxetine use, and also after a further increase to 40-50 mg day based on clinical symptoms for six more weeks, paroxetine maximally impaired platelet function at $20 \mathrm{mg}$ day. Dose escalation to $40-50 \mathrm{mg}$ day did not further influence hemostasis parameters. ${ }^{12}$ Interestingly, the mechanisms underlying the increased risk of bleeding among SSRI users seem to be the same ones that yield a protective effect against ischemic heart disease. ${ }^{1}$ Furthermore, platelet serotonin reduction is maximum in the first four to six weeks of treatment, ${ }^{13}$ which strongly suggests that the initial months of SSRI use comprise a period of higher risk of bleeding. Our cases occurred in weeks 5 and 2 after paroxetine onset. In our second case, there is no way of knowing whether the mild alterations in coagulation tests were an incidental finding or secondary to paroxetine use. Unfortunately, no baseline coagulation tests were completed before paroxetine was started, and bleeding time was not performed in either case.

As might be expected, the most frequent hemostatic abnormalities associated with SSRI use are decreased platelet activity and aggregability, and prolonged bleeding time. ${ }^{14}$ Paroxetine, fluoxetine, and sertraline, the SSRIs with highest degree of serotonin reuptake inhibition, are those antidepressants more frequently associated with modifications of hemostatic markers and abnormal bleeding. ${ }^{14}$ Interestingly, in the abovementioned study with 19 psychiatric outpatients on paroxetine treatment, the serotonin transporter gene (SCLC6A4) promoter polymorphism (5-HTTLPR) influenced the dose-response paroxetine effects on platelet function. ${ }^{12}$ Patients with the S'/S' polymorphism displayed the largest hemostatic abnormalities, such as increased 
closure time. However, in a prospective study conducted among 43 patients aged 18 to 70 years old on paroxetine therapy, serotonin transporter polymorphisms did not influence bleeding time during SSRI therapy. ${ }^{15}$ More evidence is clearly needed.

This article has limitations. First, the patients did not attribute LGIB to the use of paroxetine and continued using it. In the first patient, the psychiatrist saw the patient two weeks after the LGIB episode and recommended halving the dose. In the second patient, the psychiatrist recommended no changes because the patient disclosed the LGIB episodes several months after its occurrence. Ideally, patients should report adverse drug reactions (ADRs) at the time of its occurrence. Instead, the reality is that both health care professionals and patient underreport ADR. ${ }^{16,17}$ The systematic use of ADR may be a solution; but as gastrointestinal bleeding is an infrequent ADRs of psychotropic use, it is not included in some ADR scales. ${ }^{18}$ Second, estimating the severity of blood loss is a complicated issue. The cases reported here were classified as mild and moderate LGIB episodes. Unfortunately, laypersons are usually inaccurate when visually estimating blood loss; so are medical students, nurses and experienced physicians. ${ }^{19}$ Physicians should place enhanced attention on the clinical assessment (e.g. pulse, skin color, blood pressure) or even laboratory analysis. ${ }^{19}$ Finally, the bleeding source was not identified in either case, but hemorrhoids were ruled out as a cause of the LGIB episodes in both. Consequently, bleeding episodes were considered idiosyncratic at the time of evaluation. Unfortunately, bleeding time was not performed in either case at the LGIB time. An abnormal bleeding time suggesting a platelet abnormality would have helped to establish a causal relationship between paroxetine use and LGIB episodes. 


\section{Conclusion}

These cases demonstrate that, even if SSRIs are efficient, well-tolerated antidepressants, with putatively protective effects (e.g., from ischemic heart disease), clinicians should also be aware of the potentially lethal bleeding risk. Therefore, aged people; the concomitant use of any drug, particularly non-steroidal anti-inflammatory drugs (NSAIDs) and aspirin; and/or any medical condition that could even further increase the bleeding risk, should be a matter of concern for clinicians. For instance, valproate treatment is frequently associated with thrombocytopenia, and occasionally has been associated with disturbances in coagulation. ${ }^{20}$ Thus, it is possible that the combination of valproate with SSRIs may increase bleeding risks, but this has not been studied as far as we know. To definitively establish the association between LGIB and SSRIs, larger studies with a prospective design are needed. Until these studies are completed it seems safer for clinicians and patients to be aware that increased risk for hemorrhagic complications during SSRI treatment may include LGIB too. Warning patients about the low risk of bleeding may be advisable during the initial period of SSRI use. 


\section{References.}

1. Andrade C, Sandarsh S, Chethan KB, Nagesh KS: Serotonin reuptake inhibitor antidepressants and abnormal bleeding: a review for clinicians and a reconsideration of mechanisms. J Clin Psychiatry 2010; 71:1565-1575

2. Schlienger RG, Fischer LM, Jick H, Meier CR: Current use of selective serotonin reuptake inhibitors and risk of acute myocardial infarction. Drug Saf $2004 ; 27: 1157-1165$

3. Ottervanger JP, Stricker BH, Huls J, Weeda JN: Bleeding attributed to the intake of paroxetine. Am J Psychiatry 1994; 151:781-782

4. de Abajo FJ, Montero D, Rodriguez LA, Madurga M: Antidepressants and risk of upper gastrointestinal bleeding. Basic Clin Pharmacol Toxicol 2006; 98:304310

5. Ahsberg K, Hoglund P, Kim WH, von Holstein CS: Impact of aspirin, NSAIDs, warfarin, corticosteroids and SSRIs on the site and outcome of non-variceal upper and lower gastrointestinal bleeding. Scand J Gastroenterol 2010; 45:14041415

6. Imdahl A: Genesis and pathophysiology of lower gastrointestinal bleeding. Langenbecks Arch Surg 2001; 386:1-7

7. Naranjo CA, Busto U, Sellers EM, Sandor, P, Ruiz I, Roberts EA, Janecek E, Domecq C, Greenblatt DJ: A method for estimating the probability of adverse drug reactions. Clin Pharmacol Ther 1981; 30:239-245

8. Carvajal A, Ortega S, Del Olmo L, Vidal X, Aguirre C, Ruiz C, Conforti A, Leone R, Lopez-Vazquez P, Figueiras A, Ibanez L: Selective serotonin reuptake inhibitors and gastrointestinal bleeding: a case-control study. PLoS One 2011; 6:e19819 
9. Wessinger S, Kaplan M, Choi L, Williams M, Lau C, Sharp L, Crowell MD, Keshavarzian A, Jones MP: Increased use of selective serotonin reuptake inhibitors in patients admitted with gastrointestinal haemorrhage: a multicentre retrospective analysis. Aliment Pharmacol Ther 2006; 23:937-944

10. Narayan M, Anderson G, Cellar J, Mallison RT, Price LH, Nelson JC: Serotonin transporter-blocking properties of nefazodone assessed by measurement of platelet serotonin. J Clin Psychopharmacol 1998; 18:67-71

11. Hergovich $\mathrm{N}$, Aigner $\mathrm{M}$, Eichler $\mathrm{HG}$, Entlicher J, Drucker C, Jilma B: Paroxetine decreases platelet serotonin storage and platelet function in human beings. Clin Pharmacol Ther 2000; 68:435-442

12. Abdelmalik N, Ruhe HG, Barwari K, van den Dool EJ, Meijers JC, Middeldorp, S, Buller HR, Schene AH, Kamphuisen PW: Effect of the selective serotonin reuptake inhibitor paroxetine on platelet function is modified by a SLC6A4 serotonin transporter polymorphism. J Thromb Haemost 2008; 6:2168-2174

13. Wgner A, Montero D, Martensson B, Siwers B, Asberg M: Effects of fluoxetine treatment of platelet 3H-imipramine binding, 5-HT uptake and 5-HT content in major depressive disorder. J Affect Disord 1990; 20:101-113

14. Halperin D, Reber G: Influence of antidepressants on hemostasis. Dialogues Clin Neurosci 2007; 9:47-59

15. Hougardy DM, Egberts TC, van der Graaf F, Brenninkmeijer VJ, Derijks LJ: Serotonin transporter polymorphism and bleeding time during SSRI therapy. Br J Clin Pharmacol 2008; 65:761-766

16. Brown P, Faloon L: The incidence and reporting of adverse drug reactions in the Division of Psychiatry. Pharm World Sci 2001; 23:181-182 
17. Tuninger E, Levander S: Neuropsychological impairment in patients treated with depot neuroleptics: a longitudinal study. Acta Psychiatr Scand 2001; Suppl $408: 75-80$

18. Lingjaerde O, Ahlfors UG, Bech P, Dencker SJ, Elgen K: The UKU side effect rating scale. A new comprehensive rating scale for psychotropic drugs and a cross-sectional study of side effects in neuroleptic-treated patients. Acta Psychiatr Scand 1987; Suppl 334:1-100

19. Tebruegge M, Misra I, Pantazidou A, Padhye A, Maity S, Dwarakanathan B, Donath S, Curtis N, Nerminathan V: Estimating blood loss: comparative study of the accuracy of parents and health care professionals. Pediatrics 2009; 124:e729-e736

20. Kose G, Arhan E, Unal B, Ozaydin E, Guven A, Sayli TR: Valproate-associated coagulopathies in children during short-term treatment. J Child Neurol 2009; 24:1493-1498 